\title{
Acceptance of a Healthier Substitute for Regular Pepperoni Pizza among Campus Consumers
}

\author{
Keiko Goto and Stephanie Bianco-Simeral \\ California State University, Chico
}

\begin{abstract}
One of the best selling items in campus dining facilities is pepperoni pizza, which typically contains high levels of calories, sodium and fat. Excessive consumption of calorie- dense and sodium and fat-laden foods is associated with higher risks for some chronic diseases. Altering the amounts of ingredients used can significantly improve the nutrient composition of these foods. The purpose of this study was to examine the consumer acceptance of a top-selling university pizza with different amounts of cheese and crust. Six treatments of pizza were prepared including regular crust and $100 \%$ cheese, regular crust and $75 \%$ cheese, regular crust and $50 \%$ cheese, thin crust and $100 \%$ cheese, thin crust and $75 \%$ cheese, and thin crust and $50 \%$ cheese. The pizza treatments were evaluated using untrained panelists $(n=84)$ with a hedonic scale to measure acceptance. Analysis of variance was used to establish significant differences among the pizza treatments. The pizza with thin crust and $75 \%$ cheese was the most preferred pizza, followed by regular crust with $75 \%$ cheese. The effect of cheese on consumer acceptance was significant. Our research indicates that campus consumers may accept a healthier substitute for regular pepperoni pizza by altering the amounts of cheese and crust.

(C) 2011 Californian Journal of Health Promotion. All rights reserved.

Keywords: Pepperoni Pizza, Consumer Acceptance, Sensory evaluation, college students, nutrition
\end{abstract}

\section{Introduction}

Overweight and obesity rates of US college students have tripled from $12 \%$ in 1991 to $36 \%$ in 2004 (Ogden, Carroll, Flegal, 2006). The availability of readily available convenience food items, such as pizza, appears to be associated with obesity among college students (Mokdad, Serdula, Koplan, 1999).

Pizza is considered one of the best selling foods in the United States. According to various sources, 1) $93 \%$ of Americans eat at least one pizza per month; 2) three billion pizzas are sold in the U.S. annually; 3) America's favorite topping is pepperoni; and 4) Americans have been shown to consume an average of over 1400 calories from pizza at one sitting (Benfeld, 2009). Even in these tough economic times, a recent 2009 industry census report indicates that over $68 \%$ of pizza companies have either maintained or increased sales (Green, 2009). In
2002, a USDA's Economic Research Service report indicates that Pizza Hut maintained its status as the $5^{\text {th }}$ highest selling foodservice operation in the US with over $\$ 5$ billion in sales (Harris and others 2002). Pizza is served in 38\% of full-service restaurants and $26 \%$ of quickserve operations, and it is the seventh-mostcommon menu item in today's foodservice industry (Fricke-Stallsmith, 2003). College students, specifically in a northern California university, are no exception (Lone, Pence, Levi, Chan, Bianco-Simeral, 2009; Schuster 2008; Green, 2004; Levi, Chan, \& Pence, 2006).

\section{Nutritional composition of pizza}

The nutritional composition of pizza varies by manufacturer, but typically contains relatively excessive amounts of calories, sodium, and saturated fat, primarily due to the large amounts of cheese and crust thickness. Typical pizza slices are approximately $110 \mathrm{~g}$ or $1 / 8$ of a 14 " pie (Domino's Pizza, 2009). After controlling for 
pizza weight (in grams), the three leading pizza chains in the US, namely Domino's Pizza, Papa John's and Pizza Hut, produce a 1/8 pepperoni pizza slice from a 14" pie with an average of $325 \mathrm{kcal}, 700 \mathrm{mg}$ sodium, $12 \mathrm{~g}$ total fat, and $6 \mathrm{~g}$ saturated fat. If an American were to consume this one slice, once a month, the nutrient composition would not have a significant impact on the overall health of an individual. However, typical pizza servings can exceed 4 slices per meal and can be consumed more than 2 times per week (Just and Wansink, 2008; Werning and Baltzer 1988; Pereira et al., 2005) This potentially excessive intake would equate to a 4fold increase in the calories, sodium, total fat, and saturated fat listed above, thus exceeding the daily limit for all of these nutrients and contributing to obesity-related health conditions (Moore, 2005; Hurley and Liebman, 2002).

\section{"Stealth health" Approach}

It is well documented that foods can be made healthier by using ingredients or amounts of ingredients with less calories, sodium, and saturated fat without the consumer knowing. This is known as the 'stealth health' approach (Tribole 1999; Wagner, 2007; Lone, Pence, Levi, Chan, Bianco-Simeral, 2009). For example, in the study by Montesano and others (2006), the trained panelists could not detect a difference between the $100 \%$ high-gluten flour and the $100 \%$ high-gluten plus flax crust when the pizza samples were eaten with the toppings. However, little is known about the effects of the stealth health approach on consumer acceptance. Considering the high consumption of pizza, the current nutrient content in pizza, and the issues of chronic disease in this country, understanding the consumer acceptance of "healthier" pizza may have great significance.

Altering the dough and cheese content in a pizza in order to make it a healthier (e.g. lower calorie) pizza can be achieved by either using less of each ingredient or by using healthier ingredients, such as low-fat cheese or meat. For example, pizza made with less cheese and lessdough (thin crust) may create a significant calorie, sodium, and saturated fat deficit.
However, research shows that low-fat and fat free cheeses may negatively alter consumer acceptance (Levis, Chambers, \& Johnson, 2000). These cheeses may also be expensive due to the elaborate nature of their creation, which supports our rationale for using less cheese instead of reduced fat cheese in the pizza treatments being designed. Recipe modifications of pizza using less cheese and dough may contribute to supporting weight management goals and reducing obesity rates through lower calorie food choices, although no experimental research has been conducted to test that hypothesis.

\section{Study Objective}

In our study we chose to modify the amounts of cheese and crust of the university Dining Services' pepperoni pizza to make it a healthier pizza that is accepted by consumers. The purpose of our study was to examine whether the modification of the cheese and/or crust would affect the consumer acceptance of the pizza. Two variations on the crust and three on the cheese were employed. We hypothesized the healthier pizza modified by using less cheese and the thin crust would be as acceptable as the original pizza. Too much salt added to food may hinder other flavors and may negatively affect other product attributes, such as texture, consistency, appearance and mouth-feel (James, Ralph, \& Sanchez-Castillo, 1987). Reducing the crust and cheese content of the pizza lowers its salt content, as shown in Table 2. Thus, it was thought that the flavors of the sauce and toppings would be enhanced partially due to slightly lowering the salt content.

Furthermore, by reducing the amount of dough used for the crust, the pizza will tend to be crispier which has been shown to be a desired texture for many consumers (Green, 2008). Therefore, if these recipe modifications are accepted by consumers without knowing the recipe's nutrient content or relative healthfulness, the stealth health approach could be utilized by pizza manufacturers without fear of lost sales. By using less cheese and dough, a significant drop in food cost may also occur, and total profit may rise 
Table 1

Characteristics of pepperoni pizza treatments

\begin{tabular}{|c|c|c|c|c|c|c|}
\hline \multirow[b]{2}{*}{ Ingredients* } & \multicolumn{6}{|c|}{ Treatments } \\
\hline & $\begin{array}{c}\text { Control } \\
(\# 1)\end{array}$ & $\begin{array}{l}\text { Thick crust, } \\
75 \% \text { cheese } \\
\text { (\#2) }\end{array}$ & $\begin{array}{l}\text { Thick crust, } \\
50 \% \text { cheese } \\
\text { (\#3) }\end{array}$ & $\begin{array}{l}\text { Thin crust, } \\
100 \% \text { cheese } \\
(\# 4)\end{array}$ & $\begin{array}{l}\text { Thin crust, } \\
75 \% \text { cheese } \\
\quad(\# 5)\end{array}$ & $\begin{array}{l}\text { Thin crust, } \\
50 \% \text { cheese } \\
\text { (\#6) }\end{array}$ \\
\hline $\begin{array}{l}\text { Dough } \\
\text { Raw, commercial, 16" round } \\
\text { pies, frozen }(\mathrm{g})\end{array}$ & 695.0 & 695.0 & 695.0 & 500.0 & 500.0 & 500.0 \\
\hline $\begin{array}{l}\text { Sauce } \\
\text { Tomato, provided by campus } \\
\text { food service staff }(\mathrm{oz})\end{array}$ & 4.5 & 4.5 & 4.5 & 4.5 & 4.5 & 4.5 \\
\hline $\begin{array}{l}\text { Cheese } \\
\text { mozzarella and cheddar diced } \\
\text { mix (g) }\end{array}$ & 397.0 & 297.8 & 198.5 & 397.0 & 297.8 & 198.5 \\
\hline $\begin{array}{l}\text { Pepperoni } \\
\text { Slices, pork, full-fat brand/ } \\
\text { variety (oz) }\end{array}$ & 113.4 & 113.4 & 113.4 & 113.4 & 113.4 & 113.4 \\
\hline $\begin{array}{l}\text { Cornmeal } \\
\text { Sprinkled on pizza stones } \\
\text { before baking (g) }\end{array}$ & 5.0 & 5.0 & 5.0 & 5.0 & 5.0 & 5.0 \\
\hline
\end{tabular}

(Lone, Pence, Levi, \& Chan, Bianco-Simeral, 2009).

\section{Methods}

\section{Pizza formulation}

Six treatments of pizza were prepared: 1) $100 \%$ dough (thick crust) and $100 \%$ cheese as a control, 2) $100 \%$ dough (thick crust) and $75 \%$ cheese, 3) $100 \%$ dough (thick crust) and 50\% cheese, 4) $75 \%$ dough (thin crust) and $100 \%$ cheese, 5) $75 \%$ dough (thin crust) and $75 \%$ cheese, and 6) 75\% dough (thin crust) and 50\% cheese. This last preparation had the lowest amount of calories, sodium, and saturated fat (Table 1).

The procedures used for preparing the six pizza treatments were identical. First, the pizza stone was placed in a $500^{\circ} \mathrm{F}$ preheated oven to ensure consistent temperature control when baking the pizzas. The pizza dough, pizza sauce, and cheese used were provided by campus dining facility to mimic the same pizza sold on campus. The preformed pizza pies were removed from the laboratory refrigerators right before pizza production to prevent sticking and premature rising. For $75 \%$ dough, special care was taken to cut the uncooked dough from the outer circumference leaving $500 \mathrm{~g}$ of dough and a 16 " diameter. Reforming the dough into a ball and weighing and re-shaping the dough were not done so that additional gluten formation would not occur to potentially alter the final-baked crust texture. Similar to the college concession, a crust was formed by folding over approximately $1 / 2$ " of the dough from the outer edge and pressing it to stick.

While the oven was preheating, a scale was tared for weighing out the ingredients. Five grams of cornmeal, 127.6 grams of sauce, and 113.4 grams of pepperoni were weighed out. The weights for the amount of cheese on each pizza were as follows: Treatments \#1 and \#4: 397 grams, Treatments \#2 and \#4: 297.75 grams, and Treatments \#3 and \#6: 198.5 grams. Once the oven was preheated, the stone was removed and placed on a towel in order to protect the laboratory counter. Cornmeal was then sprinkled evenly over the hot stone. The pizza dough was placed on the stone, and pre-measured sauce was 
spread evenly over the dough with a spatula, but not on the outer crust. It was important not to get sauce on the pizza edge or stone because of potential burning and altering of flavor and aroma. The pre-measured cheese (differing amounts for each treatment) was then sprinkled evenly over the sauce. Pepperoni was then evenly distributed over the cheese.

The pizza, along with the pizza stone, was then placed on the middle rack of the same oven. The pizza was baked for approximately 15 minutes, rotating 120 degrees every 5 minutes to ensure even baking. When the pizza was completely cooked, it was taken out of the oven and placed on the protected counter. The pizza rested for five minutes before cutting and serving.

\section{Nutrition Analysis and Sensory Evaluation}

Nutritional analysis was generated with Nutrition Facts product labels, Diet Analysis Plus, Version 6.0 and verified by the USDA National Nutrient Database for Standard Reference.

The nutrition composition for calories (kcal), total fat $(\mathrm{g})$, saturated fat $(\mathrm{g})$, and sodium $(\mathrm{mg})$ was calculated for the six pizza treatments. A 9point Hedonic Scale, ranging from (9) 'like extremely' to (1) 'dislike extremely' was used for our sensory evaluation to measure consumer acceptance.

Sensory evaluation preparation included: 1) an evaluation room set-up with isolation booths, chairs, and red lights; 2) sample cups labeled with 3-digit random numbers for all treatments; 3) samples of uniform pieces from the center of each pizza pie treatment; and 4) serving trays containing six treatment samples, napkin, one cup of water, a pencil, and an evaluation survey. In addition, the three-digit pizza identification numbers were assigned in random order in order to reduce potential bias caused by similar treatment positions.

A minimum of approximately 75 participants was required to conduct a 9-point scale hedonic test with consumers for a tolerable level of risk (Lawless and Heymann 1998). Eighty-four untrained panelists, including students, faculty and staff from a medium-size university were recruited on campus to participate in the sensory evaluation test. Approximately $75 \%$ of the panelists were male and $85 \%$ were white, nonHispanic. Each panelist evaluated 6 pizza treatments with the 9-point Hedonic Scale. The panelists were instructed to taste samples from left to right and to take a sip of water before and after each sample. Panelists were instructed not to re-taste any sample. The panelists rated each sample using the corresponding numbers on their surveys. This study was approved by the Institutional Review Board at California State University, Chico.

\section{Statistical Analysis}

The sensory evaluation data were analyzed as a complete-block design. Panelists were considered random effects, and the amounts of cheese and crust were considered fixed effects (Lawless and Haymann, 1998). The dependent variable was a pizza treatment's acceptance rate. The independent variables included the type of treatment the type of crust, the amount of cheese, and the interaction of crust and cheese. Analysis of variance (ANOVA), followed by Tukey's multiple comparison tests, was performed to examine the effect of the type of pizza on consumer acceptance. The effects of crust and cheese on consumer acceptance was also examined using a mixed model ANOVA, in which the type of crust and the amount of cheese were treated as fixed effects while panelists were treated as a random effect. An interaction term between the type of crust and the amount of cheese was also included in the model. SPSS software (version 15.0 for Windows, SPSS, Chicago, Ill., U.S.A.) was used to analyze the data.

\section{Results}

\section{Nutrition Analysis of Pizza Treatments}

Table 2 demonstrates the nutritional composition of pizza per serving among the six treatments. Nutrition analysis indicated that the healthiest pizza had 205 less calories, 9.5 grams less total fat, 5.9 grams less saturated fat and 411 milligrams less sodium than the original control pizza as shown in Table 2. Although using thin crust reduces calories and sodium by 
Table 2

Nutritional composition of pizza per serving

\begin{tabular}{|c|c|c|c|c|}
\hline Treatment & Calories (kcal) & Total Fat (g) & Saturated Fat (g) & Sodium (mg) \\
\hline Control (\#1) & 566 & 18.0 & 9.7 & 1572 \\
\hline $\begin{array}{l}\text { Thick crust } \\
75 \% \text { cheese }(\# 2)\end{array}$ & 517 (49) & $13.8(4.2)$ & $7.5(2.2)$ & 1469 (103) \\
\hline $\begin{array}{l}\text { Thick crust } \\
50 \% \text { cheese (\#3) }\end{array}$ & 468 (98) & 9.5 (8.5) & $5.3(4.4)$ & 1364 (208) \\
\hline $\begin{array}{l}\text { Thin crust } \\
100 \% \text { cheese }(\# 4)\end{array}$ & 455 (111) & $17.0(\mathbf{1 . 0})$ & $9.1(\mathbf{0 . 6})$ & $1341(\mathbf{2 3 1})$ \\
\hline $\begin{array}{l}\text { Thin crust } \\
75 \% \text { cheese (\#5) }\end{array}$ & 399 (167) & 12.8 (5.2) & $6.9(\mathbf{2 . 8})$ & $1252(\mathbf{3 2 0})$ \\
\hline $\begin{array}{l}\text { Thin crust } \\
50 \% \text { cheese (\#6) }\end{array}$ & 361 (205) & $8.5(9.5)$ & $4.6(\mathbf{5 . 1})$ & $1161(411)$ \\
\hline
\end{tabular}

Serving size $=1 / 6$ of 16 " pizza

Nutrient difference between control and treatment is indicated in (bold).

approximately $20 \%$ and $15 \%$ respectively, it reduces total fat and saturated fat by only approximately $6 \%$. On the other hand, using $50 \%$ less cheese reduces calories, total fat, saturated fat and sodium by $17 \%, 47 \%, 45 \%$ and $13 \%$ respectively.

\section{Sensory Evaluation}

Table 3 demonstrates the mean values of the 6 pizza treatments. Overall, the most preferred pizza treatment was the thin crust pizza treatment with $75 \%$ cheese among our panelists with a mean of 7.1 , which translates to an overall opinion of between "Like moderately" and "Like very much." Of the other five treatments, the control, thick crust with $75 \%$ cheese, thick crust with $50 \%$ cheese, thin crust with $100 \%$ cheese, and thin crust with $50 \%$ cheese were perceived to be similarly acceptable options by the campus consumers, with mean scores of 6.6, 6.8, 6.5, 6.5, and 6.7, respectively (Table 3). Tukey's multiple comparisons test revealed that there was no significant difference in the mean values among the six pizza treatments.

Based on the mixed model ANOVA, in which the amount of cheese and the type of crust were considered fixed effects, it was found that the effect of cheese on consumer acceptance was highly significant $(\mathrm{F}=5.31 ; \mathrm{p}=0.005)$, while the crust type was not a significant factor $(\mathrm{F}=2.16$; $\mathrm{p}=0.142$ ). There was no significant interaction effect between amount of cheese and crust thickness $(\mathrm{F}=1.03 ; \mathrm{p}=0.357)$. Tukey's multiple comparison tests revealed that the $75 \%$ cheese pizza treatments were significantly more preferred over the $50 \%$ and $100 \%$ cheese pizza treatments (Figure 1).

\section{Discussion}

Excessive consumption of calorie-dense and fatladen foods of foods, such as pizza, served on campus may be associated with higher risks for obesity among college students. Altering the amounts of certain ingredients used for those campus foods can significantly improve the nutrient composition of these foods. To our knowledge, this is the first study that examined a healthier substitute for regular pepperoni pizza among campus consumers. Our study results support our hypothesis that the healthier pizza modified by using less amount of cheese and the thin crust with fewer calories (Table 2) would be as acceptable as the original pizza.

We also found that the effect of cheese on consumer acceptance was highly significant, while the crust type was not a significant factor. 
Interestingly, the $75 \%$ cheese pizza treatments were significantly more preferred over the $50 \%$ and $100 \%$ cheese pizza treatments in our study. It is uncertain whether the significantly higher acceptance of the $75 \%$ cheese pizza treatments compared to the $50 \%$ and $100 \%$ pizza treatments are related to the melt ability of cheese during contact with pizza sauce (Wang, Kindstedt, Gilmore, \& Guo, 1998) or other factors such as total fat content.

\section{Figure 1}

Mean hedonic preference of pizza treatments with various amounts of cheese.

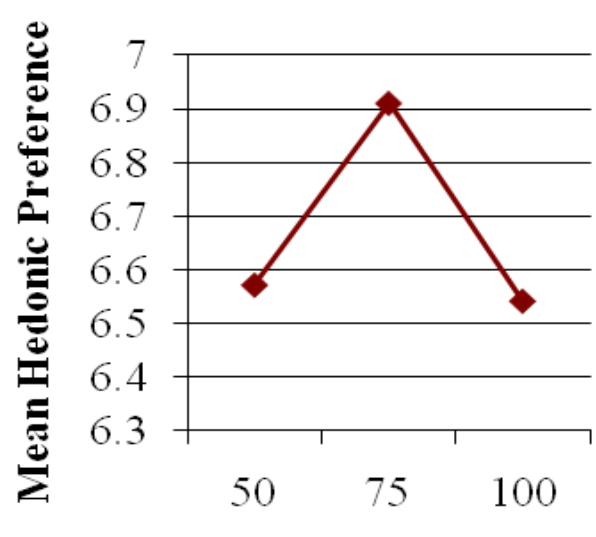

Amount of Cheese (\%)

Different letters show significant differences according to Tukey's test $(\mathrm{P}<0.05)$. $\mathrm{N}=84$.

Further research is needed to identify specific factors affecting the highest acceptance of the $75 \%$ cheese pizza. In summary, our study findings indicate that dough and cheese are two potential ingredients that may be modified for the "stealth health" approach, and with 75\% cheese, acceptance of the modified pizza may become even higher than the original pizza among consumers.

There are some implications for marketing a healthier version of pizza among health practitioners. Many students on this campus choose campus foods based on taste, rather than the healthfulness or nutrition, (Levi, Chan, \& Pence, 2006; Boek, 2009).
Table 3

Mean acceptance values of the six pizza treatments $(n=84)$

Pizza Treatments

Acceptance

Control (\#1)

$6.6 \pm 1.8$

Full crust, $75 \%$ cheese (\#2)

$6.8 \pm 1.9$

Full crust, $50 \%$ cheese (\#3)

$6.5 \pm 3.2$

Thin crust, $100 \%$ cheese (\#4)

$6.5 \pm 2.9$

Thin crust, $75 \%$ cheese (\#5)

$7.1 \pm 1.9$

Thin crust , $50 \%$ cheese (\#6)

$6.7 \pm 2.3$

All values are mean \pm standard deviation.

Tukey's multiple comparisons test revealed that there was no significant difference in the mean values among the 6 pizza treatments.

Acceptance score: $1=$ dislike extremely, $9=$ like extremely

Therefore, taste has been the primary focus of the marketing and products sold on this campus. Our sensory study results indicate that students may perceive the lower calorie versions of pizza to be as tasty as that being sold on campus. Research shows that the contrast between sensory pleasure and health play a substantive role in consumer food choice decisions, and a more comprehensive understanding of these factors is necessary (Tepper and Trail, 1998).

Further research is needed to determine strategies for promoting pizza using the concept of 'stealth health' (Tribole 1999; Wagner 2007; Lone, Pence, Levi, Chan, Bianco-Simeral, 2009) or using effective health and nutrition marketing techniques. Some successful social marketing strategies, including promoting frequent exposures to a product through advertising at the point-of-selection, have been reported (Bergen and Yeh, 2006; Conklin, Cranage, Lambert, 2005). While research presents mixed findings on how posted diet and health information influences taste, other researchers indicate that posted health and diet information may actually improve the perceived taste if the foods are typically less healthy and hedonic (Wansink and others 2004), such as pizza.

The health benefit of modifying the crust or amount of cheese in pizza depends upon the 
health concerns of the individual and consequent nutrient requirements. For example, if the individual is concerned with weight management, calories would be his/her primary concern. Similarly, individuals who have high blood lipids may benefit from choosing pizza with reduced saturated fats (Hurley and Liebman, 2002).

There are several limitations in our study. First, convenience sampling was used instead of random sampling. Thus, the study results cannot be extrapolated into the entire campus population. Second, although each panelist received pizza treatments with the same temperature, the temperature of the treatments was not always consistent among panelists. This temperature inconsistency among panelists might have slightly affected panelists' overall acceptance rates.

\section{Conclusion}

Many people correlate "healthy" versions of food with poor taste. However, our study findings suggest that university consumers may accept healthier versions of pepperoni pizza. Healthy pizza substitutions have fewer calories, saturated fat and sodium per slice than traditional pizza which may have positive impacts on a person's health. Because pizza is more popular than ever in this country, the significance of promoting healthier pizza for public health needs to be taken into consideration.

In conclusion, the $75 \%$ cheese pizza was preferred over the control among our study participants, and, therefore, would be the acceptable healthier replacement for the pizza served through the campus dining facilities. This indicates that campus consumers may accept a healthier substitute for regular pepperoni pizza. For further research, obtaining information regarding the sensory panelists' perceptions of healthiness and taste of pizza will help better understand the link between perceived liking of healthy pizza and actual liking using sensory evaluations.

\section{Acknowledgements}

The study was supported by the Department of Nutrition and Food Sciences at California State University, Chico. No competing financial interests exist. We thank our study participants and research assistants for their support.

\section{References}

Benfeld, C. (2009). Fun pizza facts. Pizza, Pasta \& Italian Food Association. Retrieved from: http://www.papa.org.uk/information_centre/general/fun_pizza_facts.shtml. Accessed August 28 2009.

Bergen, D. \& Yeh, M.C.(2006) Effects of energy-content labels and motivational posters on sales of sugar-sweetened beverages: stimulating sales of diet drinks among adults study. Journal of the American Dietetic Association, 106(11),1866-1869.

Boek, S. (2009). A sensory evaluation of pepperoni pizza as altered by the amount of cheese and type of meat. California State University, Chico. Unpublished data.

Conklin, M.T., Cranage D.A., Lambert, C.U. (2005). Nutrition Information at the Point of Sale Affects Food Chosen by High School Students. Journal of Child Nutrition \& Management, 29(1)

Domino's Pizza (2009). Domino's Pizza Nutrition Guide. Domino's IP Holder LLC. Available from: http://cache.dominos.com/homev8/docs/menu/dominos_nutrition_v2.21.00.pdf. Accessed July 1, 2010.

French, S.A., Story, M., Jeffery, R.W. (2001). Environmental influences on eating and physical activity. Annual Review of Public Health, 22, 309-335.

Fricke-Stallsmith, D. (2003). Thinking outside the (pizza) box. Food product design. Retrieved from: http://www.foodproductdesign.com/articles/2003/06/thinking-outside-the-pizza-box.aspx. Accessed June 5, 2010.

Green, S. (2004). Exclusive! University Marketing 401. PMQ's Pizza Magazine. p. 2.

Green, S. (2009). Pizza industry census report. PMQ's Pizza Magazine. p. 22-26. 
Green, S. (2008). Pizza power report 2008. PMQ's Pizza Magazine. p. 50-59.

Harris, J.M., Kaufman, P.R., Martinez, S.W., Price, C. (2002). The U.S. food marketing system, 2002: Competition, coordination, and technological innovations into the 21st century. USDA, Economic Research Service. Retrieved from: http://ideas.repec.org/p/ags/uerser/34001.html. Accessed June $5,2010$.

Hurley, J. \& Liebman, B. (2002). What a pizza delivers. Nutrition Action Health Letter, 29,1-6.

James, W.P., Ralph, A., Sanchez-Castillo, C.P. (1987). The dominance of salt in manufactured food in the sodium intake of affluent societies. Lancet, 1(8530), 426-429.

Just, D.R. \& Wansink, B. (2008). The fixed price paradox: Conflicting effects of 'all-you-can-eat' pricing. Available from: http://agnr.umd.edu/departments/AREC/Department/Seminars/2008 2009/AYCE\%206-13-08.pdf. Accessed July 1, 2010.

Lawless, H.T., Heymann, H. (1998). Sensory evaluation of food principles and practice. 3rd ed. New York: Chapman and Hall, pp 387.

Levi, A., Chan, K.K., Pence, D. (2006). Real men do not read labels: The effects of masculinity and involvement on college students' food decisions. Journal of American College Health, 55(2):9198.

Levis, P.A., Chambers, E., Johnson, D.E. (2000). Consumption and liking of a fat modified product during short trial periods. Nutrition Reviews, 20(6),791-804.

Lone TA, Pence D, Levi AE, Chan KK, Bianco-Simeral S. (2009). Marketing healthy food to the least interested consumers. Journal of Foodservice, 20(2),90-99.

Mokdad, A.H., Serdula, M.K., Koplan, J.P.(1999). The spread of the obesity epidemic in the United States, 1991-1998. Journal of American Medical Association, 282(15), 19-1522.

Montesano, M., Duffrin, M.W. \& Heidal,.K. (2006). Consumer acceptance of pizza and pizza crust made with whole wheat flour and added flaxseed. Journal of the American Dietetic Association 106(8), A55.

Moore, M.C. (2005). Pocket guide to nutritional assessment and care. 5th ed. St. Louis: Elsevier Mosbly. $640 \mathrm{p}$.

Ogden, C.L., Carroll, M.D., Flegal, K.M.(2006). Prevalence of overweight and obesity in the United States, 1999-2004. Journal of American Medical Association, 295(15),49-1555.

Pereira, M.A., Kartashov, A.I., Ebbeling, C.B., Van Horn, L., Slattery, M.L., Jacobs Jr, D.R, Ludwig, D.S. (2005). Fast-food habits, weight gain, and insulin resistance (the CARDIA study): 15-year prospective analysis. Lancet, 365(9453), 36-42.

Schuster, K. (2008). Trends that defined the times. The national association of college and university food services. Campus dining today. p. 58-65. Retrieved from: http://www.nacufs.org/files/public/pdf/cdt/may08/8_trends.pdf. Accessed July 1, 2010.

Tepper, B.J., Trail, A.C. (1998). Taste or health: A study on consumer acceptance of corn chips. Food Quality and Preference, 9(4), 267-272.

Tribole, E. (1999). Stealth health: How to sneak nutrition painlessly into your diet. 1st ed. New York: Viking. 240 p.

Wagner, B., Senauer, B., Runge, C.F. (2007). An empirical analysis of and policy recommendations to improve the nutritional quality of school meals. Review of Agricultural Economics, 29(4),672688.

Wang, W., Kindstedt, P.S., Gilmore, J.A., Guo, M.R. (1998). Changes in the composition and meltability of mozzarella cheese during contact with pizza sauce. Journal of Dairy Science, 81(3), 609-614.

Wansink, B., Ittersum, K., Painter, J.E. (2004). How diet and health labels influence taste and satiation Journal of Food Science, 69(9),S340-S346.

Werning, K.K. \& Baltzer, L.E. (1988). Entree preferences of selected restaurant customers. Foodservice Research International, 5(1), 67-80. 
Author Information

* Keiko Goto, PhD

Associate Professor, Department of Nutrition and Food Sciences Assistant Director of Research and Evaluation,

Center for Nutrition and Activity Promotion

California State University, Chico

Chico, CA 95929-0002

Phone: 530-898-6767

Fax: 530-898-5586

E-mail:kgoto@csuchico.edu

Stephanie Bianco-Simeral, MS, RD

Assistant Professor, Department of Nutrition and Food Sciences Assistant Director of Center for Nutrition and Activity Promotion California State University, Chico

*corresponding author 